\title{
Restoration and Management Notes: A Beginning
}

For several years a number of us at the UW-Madison Arboretum have felt that there is a growing need for better communication between the many people who are committed to or involved in the development of ecologically sound approaches to the preservation, restoration, and management of natural areas.

During the past year, we have discussed this with friends and colleagues. We have found that they shared this feeling. We have listened to their comments and suggestions and have freely borrowed their ideas. This little journal is the result.

We hope it will do two things.

First, we hope it will encourage communication between people in the wide variety of traditional disciplines who have a commitment to restoration and management. These range from mine reclamation and wildlife ecology to forestry and landscape architecture. Traditionally there has been little effective communication between many of these groups. As a result, we believe that much valuable information pertaining to restoration and management is going to waste, that there is widespread duplication of effort in this area, and that ideas are not getting the exposure they need to grow and develop. We hope this journal will represent at least a step toward remedying this problem and that it will eventually become the forum for a highly productive, many-sided dialogue between professions.

Our second objective is closely related to the first. We hope that, in addition to bringing together professions in a new forum for the exchange of information and ideas, this publication will help identify restoration and management as a new discipline in its own right - an art, and perhaps a science, borrowing from other disciplines, but distinct from them in having its own aims, confronting different problems, raising different kinds of questions, and concerned with the development of ideas and techniques peculiarly its own.

We believe that a new discipline is taking shape in response to the growing challenge of developing better, more effective and more economical ways of restoring and managing ecosystems. We believe that this is an enterprise with immense significance not only for the environment, but, as John Cairns points out in his accompanying article, for ecology as well. And we hope to contribute to its growth and definition.

With this in mind, we want to define the ground we will be covering very carefully. What we will be dealing with will in many cases come from adjacent and contributing disciplines, but it will be distinct from them in one important respect:

Restoration and Management Notes will deal only with the restoration and management of ecological communities for essentially scientific or esthetic purposes; or in other words, with the development and preservation of ecosystems of high ecological quality.

It will, for example, deal only with the development and management of communities that are native or at least ecologically appropriate to their site, and of course with the plants and animals that make them up, with the habitat itself, and with the various factors that threaten its integrity.

Thus, we will deal with the restoration of prairies or wetlands for esthetic or experimental purposes, or as part of a habitat or watershed improvement program, but not with the management of range land for forage production.

We are eager to hear from foresters and people responsible for minesite reclamation, but will not deal with management of forests for timber production alone or with reclamation efforts aimed only at land stabilization without reference to the added task of the improvement and ecological refinement of the resulting community.

We are interested in ideas and general principles as well as facts and techniques, which is why we have not confined this journal to a single community - prairie for example-as a few persons suggested. We suspect that the development of ideas is encouraged by comparisons, by the search for similar patterns in dissimilar situations, and by interaction between practitioners and theoreticians.

In general, we intend to promote interchange of ideas. We want to make it easy to contribute and to find notices in back issues. We will try to get notes into print fast and with minimum expense. At this stage, we are happy to have heard from conservationists, researchers, managers, and naturalists at a wide variety of federal, state, and local government agencies. We have notes from ecologists, naturalists, land reclamationists, landscape architects, foresters, and managers of parks, wildlife preserves and other natural areas, and we hope to hear from many more.

We hope to help our readers keep up to date on research and new techniques. And we hope to help them get in touch with each other-hence the address and phone number accompanying each note. Restoration and Management Notes is not refereed and, initially at least, will come out on an occasional basis.

One final word: this first issue of Restoration and Management Notes is an experiment that we have undertaken at our own expense. Subsequent issues will depend on subscriptions. The response to our initial announcement has been extremely encouraging, and we are mailing more than 2,000 copies of this issue. But, in order to continue, we will need both subscribers and contributors. Please keep this in mind as you look over this first issue. A subscription reply slip is on page 39 .

WRJ 